\title{
A rede de causalidade da insegurança alimentar e nutricional de comunidades quilombolas com a construção da rodovia BR-163, Pará, Brasil ${ }^{1}$
}

\section{The causality of nutrition and food insecurity of quilombola communities with the construction of the BR-163, highway, Pará, Brazil}

Denise OLIVEIRA e SILVA²

Ana Felisa Hurtado GUERRERO ${ }^{3}$

Camilo Hurtado GUERRERO ${ }^{2}$

Luciano Medeiros de TOLEDO ${ }^{4}$

\section{R E S U M O}

\section{Objetivo}

Trata-se da descrição de resultados baseados na elaboração de um modelo de determinação causal de forma participativa e abrangente, realizada em seis comunidades quilombolas no município de Santarém, no Estado do Pará, sobre a rede de causalidade da insegurança alimentar e nutricional com a abertura da Rodovia BR-163.

\section{Métodos}

o processo investigativo utilizou métodos de abordagem sócio-antropológica tendo como base o desenvolvimento de um modelo de causalidade construído por meio da realização de grupos focais com representantes da comunidade.

\section{Resultados}

Os resultados do estudo demonstraram que a utilização de abordagens participativas estimula a auto-estima da comunidade e o empoderamento sobre os fatores que determinam seus problemas. 0 modelo causal

\footnotetext{
${ }^{1}$ Artigo elaborado a partir do projeto de pesquisa financiado pelo Ministério da Ciência e Tecnologia, Ministério da Saúde e Conselho Nacional de Desenvol vimento Científico e Tecnológico, a partir do Edital MCT/CNPq/M S-SCTIE-DECIT 034/2005 (processo CNPq no 402836/2005-7), compondo trabalhos voltados ao desenvolvimento prioritário em saúde para a Área de Influência da BR-163.

2 Diretoria Regional de Brasília da Fundação Oswaldo Cruz. SEPN, Bloco A Quadra 510, Ed. Anexo II do MS, Sala 407, 70750-520, Brasília, DF, Brasil. Correspondência para/Correspondece to: D. OLIVEIRA e SILVA. E-mail: «deniluz@fiocruz.br». ${ }^{3}$ Centro de Pesquisas Leônidas Maria Deane. Manaus, AM, Brasil.

${ }^{4}$ Escola Nacional de Saúde Pública Sérgio Arouca. Rio de Janeiro, RJ, Brasil.
} 
construído revela que a insegurança alimentar e nutricional, para as comunidades, estabelece que fatores históricos relacionados à posse da terra e ao seu uso atual baseado em práticas predatórias, são os aspectos fundamentais na compreensão da rede de determinação causal da insegurança alimentar e nutricional.

\section{Conclusão}

O racismo e suas nuances sociais têm contribuído para a invisibilidade social dessas comunidades nas políticas públicas brasileiras. As comunidades quilombolas se consideram em insegurança alimentar e nutricional e indicam que a abertura da Rodovia BR-163 pode ser uma ameaça ao etno-desenvolvimento sustentável na região. E referem que o desenvolvimento econômico esperado com a abertura desta rodovia, se não for realizado com base na participação da comunidade, pode aumentar a fome, a miséria e o racismo.

Termos de indexação: Antropologia cultural. Grupo com ancestrais do continente africano. Insegurança alimentar. Percepção social. Pesquisa qualitativa.

\section{A B S T R A C T}

\section{Objective}

This work describes results based on the participative and encompassing development of a model of causal determination done in six quilombola communities of Santarém, Pará State, regarding the causality of food and nutrition insecurity with the construction of the BR-163 highway.

\section{Methods}

The research process used socio-anthropological approach methods based on the development of a causality model constructed by forming focal groups with community representatives.

\section{Result}

The results of the study show that the use of participative approaches stimulates the community's self-esteem and takes control of the factors that determine its problems. The causal model reveals that, for the communities, nutrition and food insecurity establish that historical factors associated with land ownership and current use based on predatory practices are essential to understand the causal determination of food and nutrition insecurity.

\section{Conclusion}

Racism and its social nuances have contributed for the social invisibility of these communities in public Brazilian policies. The quilombola communities consider themselves in a state of nutritional and food insecurity and indicate that the construction of the BR-163 highway can be a threat to the sustainable ethnic development in the region. They also state that the economic development expected with the construction of this highway can increase hunger, poverty and racism if the communities do not participate.

Indexing terms: Anthropology, cultural. African continental ancestry group. Food insecurity. Social perception. Qualitative research.

\section{N T R O D U C Ã O}

Os quilombos são núcleos populacionais que, diante da condição de escravidão, constituíram formas particulares de organização social e ocuparam espaços geográficos estratégicos no Brasil $^{1}$. Estas comunidades geralmente se localizam em várias regiões do País, notadamente nas áreas rurais; apresentam um relativo grau de isolamento geográfico e vivem desigualdades sociais e de saúde. Nestas comunidades, as conseqüências históricas do processo de escravidão e a forma de sua libertação têm influenciado o acesso diferenciado a bens e serviços, constituindo-se como fatores condicionantes da situação de insegurança alimentar.

O reconhecimento legal destas comunidades foi estabelecido a partir da Constituição de 1998, no artigo 68 das disposições constitucionais transitórias, delegando à Fundação Cultural Palmares os cuidados de todas as questões referentes a quilombos. A definição de quilombos está baseada na auto-atribuição, com trajetória históri- 
ca própria, dotada de relações territoriais específicas, com a presunção de ancestralidade negra, relacionada com a resistência à opressão histórica sofrida².

O conceito de segurança alimentar e nutricional no Brasil está em construção. Seus pressupostos conceituais têm sido elaborados em razão de disputas de interesses de movimentos sociais e de governos. A noção de segurança alimentar,originalmente concebida na Europa a partir da I Guerra Mundial, vem, ao longo desses anos, assumindo contorno ampliado $0^{3,4}$.

No Brasil este conceito foi rediscutido na III Conferência Nacional de Segurança Alimentar. Neste evento, foi ratificada a dimensão do conceito de soberania alimentar ${ }^{4,5}$, que parte da visão do direito de povos e nações de produzir alimentos pela valorização das dimensões sociais, ambientais e culturais da produção própria de alimentos; da ampliação do acesso da população a alimentos de qualidade, com o apoio às formas eqüitativas e sustentáveis de produção agroalimentar; do estímulo à diversidade de hábitos alimentares; e da promoção de práticas alimentares saudáveis. 0 conceito de insegurança alimentar e nutricional está baseado nas múltiplas funções associadas à atividade agrícola e ao mundo rural, que vão além do aspecto produtivo e mercantil e têm forte associação com a forma de ocupação social do espaço geográfico, ao patrimônio natural e à herança cultural ${ }^{5}$. Nas comunidades tradicionais brasileiras, onde estão inseridas as populações quilombolas, têm sido desenvolvidas várias iniciativas governamentais e da sociedade civil para a promoção da segurança alimentar e nutricional. Dentre estas iniciativas, destaca-se a abertura da Rodovia BR-163, via expressa que ligará o Estado de M ato Grosso ao Estado do Pará. Esta rodovia tem 1780 quilômetros e atravessa um trecho com grande diversidade econômica, cultural e ambiental. 0 asfaltamento não foi totalmente concluído e cerca dos 1000 quilômetros que faltam estão localizados próximos ao município de Santarém, onde estão situadas comunidades indígenas e quilombolas.
Com o propósito de conhecer os efeitos da abertura desta rodovia para estas comunidades 0 edital do Conselho Nacional de Desenvolvimento Científico e Tecnológico, MCT-CNPQ/M S-SCTIEDECIT número 34/2005 em 2006 selecionou inúmeros projetos de pesquisa para descrever os diversos impactos da construção e da pavimentação da Rodovia BR-1636. Nesse sentido, coube à Fundação Oswaldo Cruz, por meio das unidades da Amazônia e de Brasília, descrever a percepção dos quilombolas sobre insegurança alimentar e nutricional com a abertura desta rodovia. Para obter a compreensão desse fenômeno, foram utilizadas abordagens metodológicas quantitativas e qualitativas, por meio de técnicas de geoprocessamento, epidemiológicas, demográficas e econômicas. 0 processo investigativo ainda está em curso com a adição de estudos etnográficos sobre o tema. Assim, a proposta deste artigo é descrever a rede de causalidade de insegurança alimentar e nutricional construída pela população quilombola com a abertura da Rodovia BR-163 na cidade de Santarém, no Estado do Pará, Brasil.

\section{M É TO D O S}

Trata-se de uma pesquisa qualitativa realizada em seis comunidades quilombolas no município de Santarém, no Estado do Pará, composta por 2164 habitantes. Nesta investigação, foram previstas várias abordagens e estratégias para apoiar as comunidades a obter a segurança alimentar e nutricional. Como primeira etapa, discutida com os líderes quilombolas, foi estabelecido o desenvolvimento da rede de causalidade da insegurança alimentar e nutricional com a abertura da Rodovia BR-163. Em razão dessa decisão, foi escolhido o método de investigação socioantropológica para abordagem de fatores determinantes causais por meio da participação social de atores envolvidos com o projeto ${ }^{7}$. Neste método estão previstas a realização de Grupos Focais (GF) e a construção de modelos causais para obter um enfoque global e compreensivo da insegurança alimentar e nutricional. 
A técnica de abordagem baseada na realização de GF foi escolhida pelo seu papel de permitir ao pesquisador perceber as diversas visões sobre o tema investigado. A técnica de GF é muito eficiente porque estimula a participação dos membros do grupo, com o propósito de compartilhar e discutir opiniões e sentimentos para que sejam elucidadas as diferenças e aprofundados os argumentos ${ }^{8-10}$.

O modelo causal é uma representação gráfica simplificada de um conjunto de hipóteses organizadas, de forma hierárquica, de fatores determinantes de uma situação, processo ou sistema para efetuar diagnósticos nutricionais ${ }^{10,11}$. Este instrumento permite selecionar as informações empíricas requeridas pelo diagnóstico e facilita a análise e a interpretação. 0 modelo causal deve ser construído por uma equipe multidisciplinar com participação dos atores envolvidos com a situação que será analisada, em que as regras de sua construção deverão ser pactuadas ${ }^{7,10,11}$.

0 processo foi iniciado com o envio de carta da coordenação do Projeto Quilombos da Fundação Osvaldo Cruz (Fiocruz), com a descrição dos objetivos da pesquisa e a forma de abordagem para sua execução, à Federação Quilombola de Santarém (FQS), em novembro de 2005. Nesse documento, foi sinalizado que a pesquisa previa diversos procedimentos e que inicialmente a primeira etapa consistia na realização de entrevistas com membros da comunidade e na realização de grupos focais.

Em janeiro de 2006, ocorreu uma assembléia sem a participação dos pesquisadores da Fiocruz, em que foi aprovada a realização da pesquisa e agendada, para fevereiro daquele mesmo ano, a visita dos pesquisadores para apresentar a proposta de investigação. Em fevereiro de 2006, foi apresentada a proposta e destacada a importância da realização de GF com a participação de membros da comunidade. A proposta foi aceita na assembléia e foram indicados 21 líderes co munitários. Em abril de 2006 foi composto o GF com 21 líderes comunitários e três pesquisadores, sendo 12 pessoas do sexo masculino e 11 do sexo feminino. A média de idade dos representantes da comunidade foi de 25 anos e dos pesquisadores de 40 anos.

Foram realizados cinco encontros na sede da FQS, divididos em cinco turnos de quatro horas diárias, totalizando 40 horas de trabalho. No primeiro encontro, os pesquisadores apresentaram a dinâmica do trabalho, baseada na discussão do conceito de insegurança alimentar com a abertura da Rodovia BR-163 e a construção de um modelo causal sobre esta situação. A confecção do modelo causal foi apresentada a todos os participantes, por meio da descrição dos fatores causais mais imediatos nos primeiros níveis do modelo até chegar ao(s) fator(es) básico(s) da rede de determinação causal7,10,11.

Com a apresentação finalizada, os pesquisadores convidaram os participantes a pactuarem os procedimentos gerais do trabalho no GF. Foram escolhidos os auxiliares e o desenhista do modelo causal e organizada a gravação da fita de vídeo de todo o processo. Os membros do GF aceitaram a proposta e foi designado imediatamente um facilitador, que assumiu o papel de estar atento aos participantes e demonstrar interesse às falas, ter liderança e flexibilidade quanto às sugestões oferecidas pelos membros do GF. Foi escolhido também o auxiliar encarregado de controlar 0 funcionamento do processo de filmagem, e outro para auxiliar na confecção do desenho do modelo causal.

Todos os encontros foram gravados em fita de vídeo com assinatura de um termo de autorização prévia de sessão de imagens e do termo de consentimento livre e esclarecido.

Os pesquisadores utilizaram diários de campo, com o propósito de registrar os acontecimentos antes, durante e após a atividade. Este instrumento buscou apoiar a análise do material registrado em fita de vídeo, com o propósito de registrar falas informais, linguagem corporal e outras expressões ${ }^{8,9}$. Ao fim da realização do GF foram gravadas 28 horas de imagem, convertidas em CD-ROM. 
A análise e a interpretação dos resultados da pesquisa estão em curso e utilizam como caminho as representações sociais, com vistas ao trabalho de unir a experiência vivida dos sujeitos em seu contexto de elaboração da rede causal da insegurança alimentar com a abertura da Rodovia BR-16312. Este processo foi efetuado com os participantes do GF, que discutiram e pactuaram os ramos causal que deveriam ser aprofundados para a discussão da insegurança alimentar e nutricional. Foi estabelecido que a posse da terra e a ilusão quilombola eram os aspectos causais a serem aprofundados, constituindo-se dos núcleos de sentido utilizados neste artigo.

Embora a opção metodológica da pesquisa, baseada no método das representações sociais possibilite a análise simbólica das falas dos sujeitos, para a construção deste artigo, foi priorizada a apresentação da rede de causalidade, por meio da apresentação dos modelos causais, com a utilização de depoimentos dos sujeitos de forma ilustrativa. Esta pesquisa foi aprovada pelo Comitê de Ética em Pesquisa da Fiocruz, em setembro de 2006, sob o protocolo 35106.

\section{RESULTA D OS E DISCUSSÃ O}

Em Santarém, foram identificadas seis comunidades remanescentes de quilombos. Entre estas comunidades, quatro encontram-se localizadas na área do planalto (terra firme) - Bom Jardim, M urumurutuba, M urumuru e Tiningu; e duas se localizam na área de várzea - Saracura e Arapemã. A localização das áreas quilombolas está entre $40 \mathrm{~km}$ de barco, a mais próxima (Arapemã), e $100 \mathrm{~km}$ por terra a mais distante (Bom Jardim) (Figura 1).

O contingente populacional identificado por meio do censo realizado pela Fiocruz, em 2006, é de 2164 habitantes, como demonstra a Tabela 1.

A distribuição por sexo correspondeu a $47,1 \%$ para o sexo feminino e $52,9 \%$ para o masculino. Os pesos da razão de dependência são

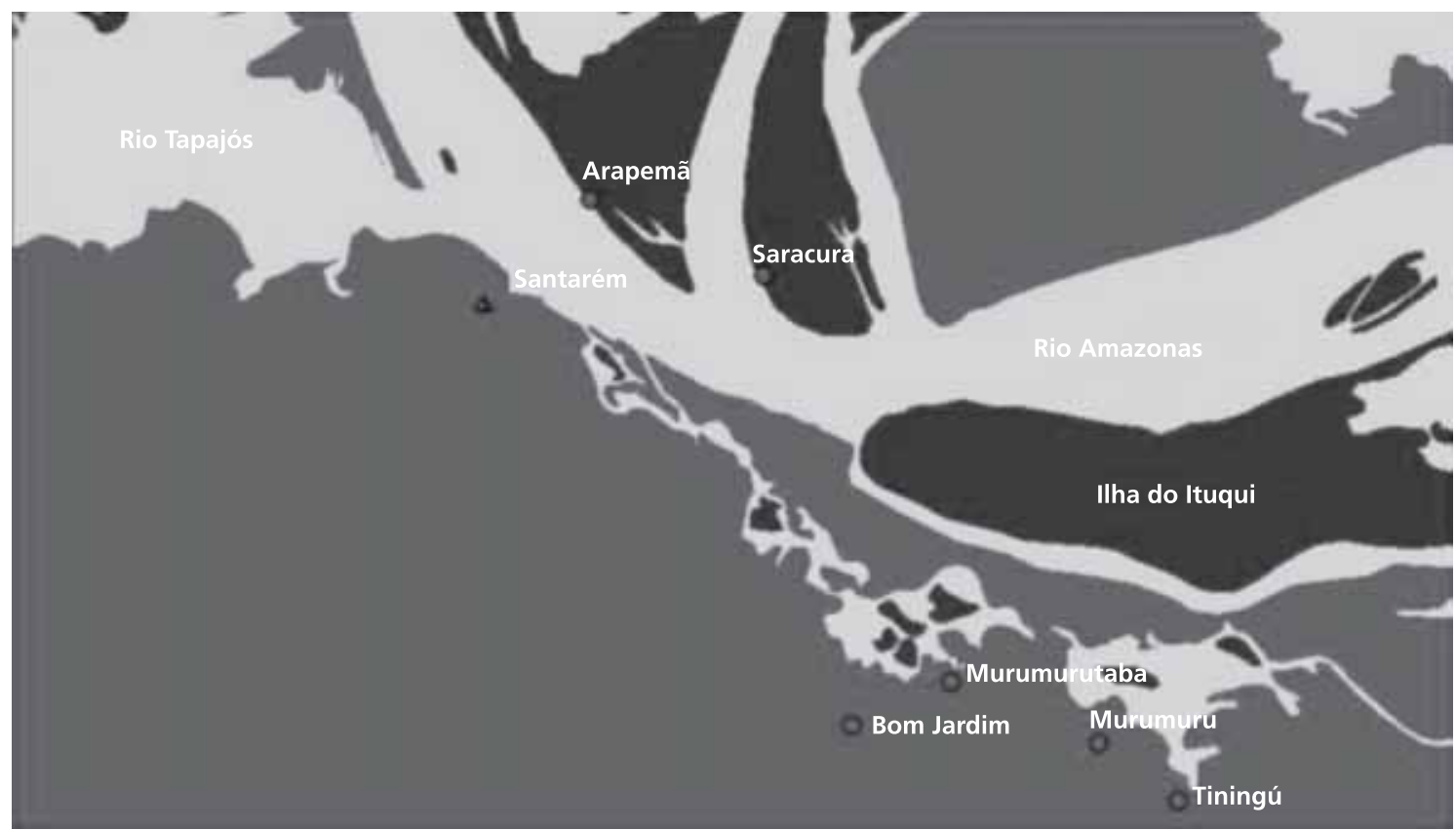

Figura 1. Localização das comunidades quilombolas.

Fonte: SEM DE/SEMAB - STM/PA, 2002 e Fundação Oswaldo Cruz ${ }^{37}$. 
Tabela 1. Distribuição absoluta e relativa da população quilombola nas seis comunidades referenciadas para o município de Santarém (PA), Brasil, 2006.

\begin{tabular}{lcccccc}
\hline \multirow{2}{*}{ Quilombo } & \multicolumn{2}{c}{ População } & & \multicolumn{2}{c}{ Famílias } \\
\cline { 2 - 3 } \cline { 6 - 7 } & $\mathrm{n}$ & $\%$ & & $\mathrm{n}$ & $\%$ \\
\hline Arapemã & 252 & 12,5 & & 59 & 11,5 \\
Bom Jardim & 312 & 15,4 & & 73 & 14,2 \\
Murumuru & 322 & 15,2 & & 72 & 14,7 \\
Murumurutuba & 371 & 16,3 & & 77 & 16,9 \\
Saracura & 596 & 26,2 & & 124 & 27,1 \\
Tiningú & 344 & 14,4 & & 68 & 15,7 \\
\hline Total & 2197 & 100,0 & & 473 & 100,0 \\
\hline
\end{tabular}

Fonte: Fundação Oswaldo $\mathrm{Cruz}^{37}$.

fortemente influenciados por crianças e jovens, com a participação muito pequena dos idosos na população. Os valores de participação dos jovens na razão da dependência estão em torno de $97,2 \%$, enquanto que para os idosos são de $12,9 \%$.

Os núcleos familiares, geralmente, são ampliados, com até 15 filhos, comportando laços de vizinhanças e familiares ou pessoas bem próximas, como filhos, avôs, irmãos, genros e noras. Geralmente, as associações ou as lideranças comunitárias são compostas por membros do núcleo familiar.

Em relação à composição étnico-racial, a presença do negro é mais forte nas comunidades do Bom Jardim e de Saracura. Nas outras comunidades observa-se maior miscigenação.

A maioria das habitações é de palhoça, madeira e algumas utilizam esses dois materiais sem divisórias de cômodos. Tiningu é o único quilombo em que predominam construções de alvenaria. Estão distribuídas em núcleos habitacionais em forma de mocambos familiares ${ }^{13}$.

0 abastecimento da água nas comunidades é proveniente de poços artesianos e de cacimbas ou nascentes, especialmente nas comunidades de planalto, enquanto nas comunidades de várzea é proveniente de rios e igarapés. Tiningu é a única comunidade que conta com água encanada, mas sem nenhum tratamento sanitário.
A maior parte das comunidades recorre à iluminação de lamparinas de querosene e nenhuma delas conta com rede de energia elétrica.

A população analfabeta não funcional (não consegue escrever sequer um bilhete) alcança $31,8 \%$, porém a população que terminou o 1 o grau do ensino fundamental é de $51,4 \%$. As escolas, em sua maioria, são multiseriadas, algumas em precário estado de conservação, e oferecem até a 8a série, motivo pelo quais alguns alunos transitam entre outras localidades para conseguir terminar a $1 \underline{\text { a }}$ série do ensino fundamental.

Com relação às fontes de renda apenas 6,2\% recebem aposentadoria, 5,4\% Bolsa Escola, 3,3\% Bolsa Família e 81,8\% não têm nenhum tipo de renda.

Essas comunidades localizadas na Amazônia habitam uma região com a maior biodiversidade e com um dos ecossistemas mais íntegros e produtivos do planeta, ao mesmo tempo em que apresentam grandes desafios para se desenvolver de forma harmônica e sustentável ${ }^{14,15}$.

O desenvolvimento da agricultura familiar é influenciado por um conjunto de condicionantes, entre os quais, o tipo de inserção socioeconômica, a localização geográfica, as oportunidades, a conjuntura econômica, as instituições e os valores culturais da família ${ }^{16}$.

Nas comunidades quilombolas brasileiras, segundo o Relatório Geral - Diagnóstico Socioeconômico-Cultural das Comunidades Remanescentes de Quilombos -, elaborado pela Fundação Cultural Palmares e a Universidade de Brasília, as condições de acesso aos alimentos, por meio da produção e pela renda, são muito precárias ${ }^{17}$.

Os territórios quilombolas foram consolidados em regiões periféricas e seu desenvolvimento foi baseado na preservação do uso comum da terra, e a produção de alimentos foi concebida por meio de práticas herdadas de seus ancestrais. São exemplos vivos de sustentabilidade ambiental, conceito incorporado ao debate da segurança alimentar e nutricional ${ }^{2,3}$. 
Em Santarém, as comunidades de Planalto vivem principalmente de cultivos agrícolas (roça), combinando esta atividade com uma incipiente produção de pecuária de subsistência. A produção é uma espécie de reserva econômica. A comercialização de seus produtos é mais direcionada para produção e venda da farinha de mandioca e de seus subprodutos no comércio central da cidade. Geralmente, os quilombolas vendem seus produtos por valores muito baixos a atravessadores, que os comercializam em Santarém. Este problema é determinado pelo isolamento da comunidade e pela ausência de meios de transporte. As comunidades de planalto contam com uma linha irregular de transporte viário que as liga a algumas comunidades e a outras localidades no município. Os ônibus estão em precárias condições e são utilizados tanto para o transporte de pessoas como para cargas e animais. Em épocas de chuva, a ausência de estradas asfaltadas determina inúmeras dificuldades de deslocamento, que são parcialmente solucionadas pelo uso de transporte fluvial, dependente das condições meteorológicas.

Nas terras de várzea, a população vive principalmente da pesca. A disponibilidade de peixes tem sido freqüentemente baixa, afetada pelo saque de terras, para produção de argila em olarias da região.

A ameaça ambiental às condições de vida dessas populações é outro aspecto destacado na compreensão dos fatores causais da insegurança alimentar e nutricional. Tanto nos quilombos de várzea como nos de terra firme, a ausência e a diminuição do peixe representam a ameaça da fome por causa da depredação ambiental.

0 peixe aqui está desaparecendo. Tem pescador que passa 15 dias atrás de peixe e volta pra casa sem nada. Há 5 anos isto não era assim. Cada ano vai ficando mais difícil. Eu acho que a natureza tá revoltada com os abusos dos homens [...] Arapemã já teve melancia e muito peixe. Agora eu não acho lugar para plantar. As terras estão caindo, por causa do roubo para fazer argila [...] (Homem, 56 anos, pescador).
A redução dos estoques pesqueiros na Amazônia tem estreita relação com a derrubada de matas ciliares, a destruição de nascentes, 0 assoreamento, a poluição e o represamento dos rios $^{14}$. Nas comunidades de várzea, essa situação é mais acentuada e se reflete na redução gradativa da disponibilidade de uma proteína de alto valor biológico, em decorrência do fenômeno denominado pelos quilombolas como "terras levadas". Este fenômeno consiste na extração indiscriminada de barro-argila para a fabricação de tijolo e telhas em olarias da região, por pessoas que não são da comunidade. Essa prática contribui para a erosão do solo com a perda de terrenos e a mudança constante de moradia das famílias quilombolas. Outra forma de depredação ambiental é referida pelo nome de "geleira". Segundo a definição local, este é um problema ecológico determinado pela pesca predatória em larga escala feita por barcos de grande porte que ocasiona buracos de terra na região, determinando a diminuição da produção de pescado.

$\mathrm{Na}$ terra firme, a produção agrícola tenta ser desenvolvida em escala de economia de mercado, com oferta de produtos, como: melancia, feijão, milho e alguns subprodutos da mandioca. Contudo, a quantidade produzida é insuficiente para alimentar a população e gerar renda durante 0 ano inteiro. $A$ base da alimentação é o peixe, a farinha de mandioca e as frutas. As aves são consumidas em ocasiões especiais e a carne bovina raramente. A carne de caça também é uma opção referida. Outros alimentos, como arroz, feijão e macarrão, são consumidos quando existe disponibilidade de renda de um ou mais membros da família. Foram observadas preparações regionais como o vinho de açaí, doces de frutas da região e a confecção da farinha do peixe (piracuí) $)^{18}$.

Os programas de suplementação alimentar governamentais identificados no momento da pesquisa entre 2003 e 2006, aos quais as comunidades têm acesso, são: Bolsa Alimentação, do M inistério da Saúde (MS), que tem a distribuição 
dos alimentos realizada em Santarém, o que obriga os quilombolas beneficiários a gastarem cerca de $70 \%$ dos recursos oferecidos pelo programa com transporte e deslocamento para o recebimento dos alimentos. O Programa de Alimentação Escolar é um programa de suplementação alimentar referido pela comunidade, como uma estratégia inadequada aos hábitos alimentares dos escolares, porque oferece somente formulados, como sopas e mingaus e tem regularidade deficiente.

Com a realidade socioeconômica e ambiental influenciada por dimensões históricas e políticas no contexto de identidade étnica, a discussão da insegurança alimentar foi debatida à luz da reflexão dos fatores de progresso ou de acirramento da exclusão social com a abertura da Rodovia BR-163.

0 reconhecimento de que as comunidades estão em insegurança alimentar foi expresso por todos os líderes comunitários que participaram do GF. Os fatores causais considerados de maior relevância foram: a falta de posse da terra; a ausência de uma renda monetária; 0 aumento de doenças; os fatores ambientais; a falta de tecnologia apropriada para pesca e obtenção de subprodutos agrícolas do açaí e da mandioca; a marginalidade e 0 analfabetismo (Figura 2).
A visão segundo a qual estar em insegurança alimentar é não ter acesso à posse de suas terras é marcante para as comunidades, tanto para atrair investimentos como para reprimir abusos relativos à depredação ambiental. Assim, a não-titulação das terras quilombolas explica, em grande parte, o reconhecimento da comunidade ao se considerar em insegurança alimentar. Este fator é a causa do impedimento para a instalação de empreendimentos com bases sustentáveis, e pode influenciar o estado nutricional das coletividades pela forma como se dão a oferta e a disponibilidade, 0 acesso, o consumo de alimentos.

A questão da titulação das terras dos remanescentes de quilombos é um ponto da pauta na agenda dos governos brasileiros, mas seu processo é lento e litigioso. Esta situação expressa o racismo institucional que tem suas raízes desde as estratégias de branqueamento da sociedade brasileira, incentivadas pela imigração de portugueses, italianos, alemães e japoneses nas regiões Sul e Sudeste no início do século XX. Estas políticas imigratórias contemplaram os estrangeiros em algumas regiões e estados do Brasil, mas foram desiguais e racistas porque não priorizaram negros e indígenas da mesma forma, tendo como conseqüência a sua exclusão social e marginalidade ${ }^{19,20}$.

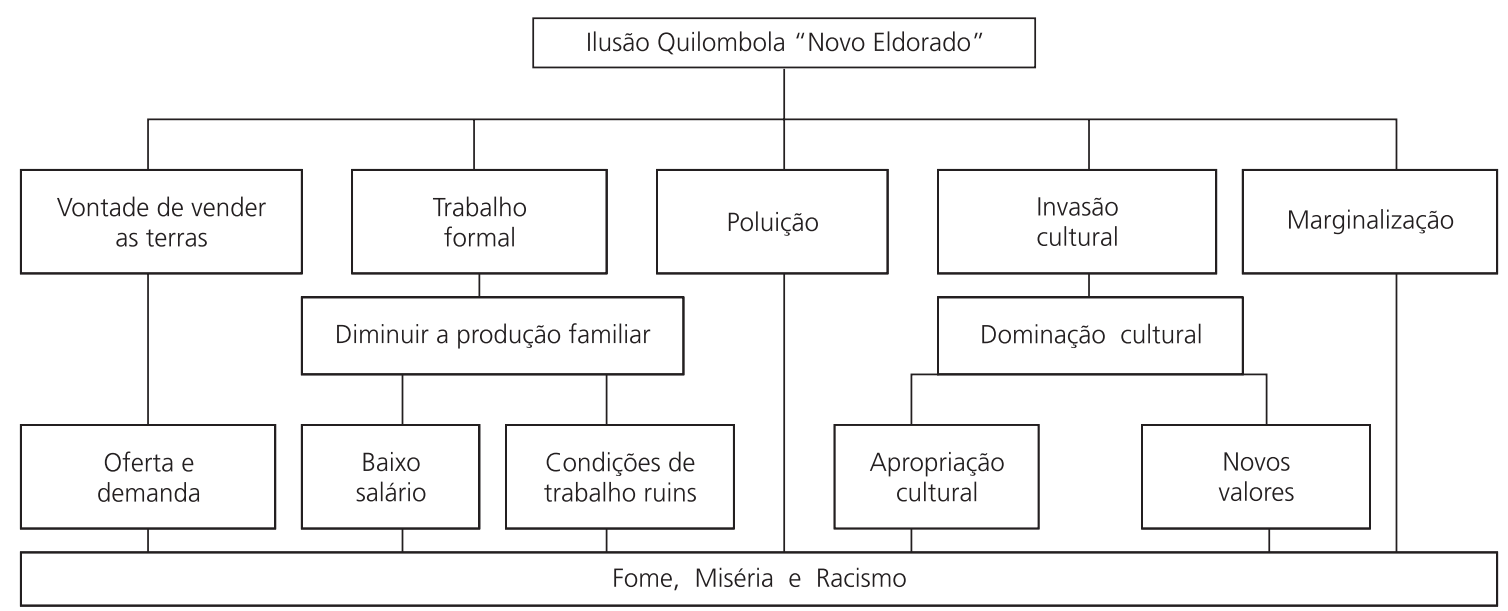

Figura 2. Modelo causal da ilusão quilombola com abertura da Rodovia BR 163 elaborado por líderes quilombolas. Santarém (PA), 2006. 
A população negra recém-liberta tinha somente os quilombos já instalados como espaços de resistência à escravidão para iniciarem sua vida como libertos. Esses territórios, em sua maioria, estavam em áreas inóspitas, porque sua origem tinha como estratégia a idéia de esconderijo ${ }^{13,19}$.

A situação fundiária dos quilombos localizados em Santarém tem a grilagem de terras e a invasão de fazendeiros como principais desafios a serem superados. Essa situação tem sido assumida pela comunidade por meio da organização coletiva, com enfrentamentos, por vezes, pela violência física, com relatos de assassinatos de lideranças quilombolas na região ${ }^{18}$.

A falta de uma renda monetária, de empregos e salários é outro aspecto na identificação dos fatores causais da insegurança alimentar e nutricional. 0 reconhecimento que a circulação monetária mais estável se dá pela aposentadoria de idosos e inválidos foi referido como única garantia mensal de renda.

Eu nunca pensei que a aposentadoria da mãe é que ia dar a nós o que comer. Todo mês eu demoro uma manhã para chegar com ela no Banco e uma tarde para voltar para casa. Aqui em Santarém não se acha trabalho. Nós vive do que ela ganha. Quando acaba, ficamos comendo o que a gente consegue pescar e a farinha que dá pra guardar [...] (Mulher, 32 anos, dona-de-casa).

A ausência de acesso à energia elétrica é considerada um fator importante para a dificuldade de emprego e renda, porque contribui para a incapacidade da comunidade em desenvolver qualquer empreendimento de cooperativas de produção. Concorrem com isto a baixa instrução e 0 analfabetismo, que impedem a apropriação de conhecimento de novas técnicas e tecnologias para o melhor manejo do pescado e de seus subprodutos.

Se nós tem apoio do governo para beneficiar nosso peixe, vender nosso artesanato, colocar escolas para nossos filhos, nossa vida ia melhorar [...] nós não temo energia elétrica para guardar o peixe; não sabemo outras técnicas para conservar o peixe; como fez o pessoal de Oroximiná [...] nós não vira marginal por obra de Deus. (Homem, 37 anos, pescador).

As categorias profissionais mais freqüentes nas comunidades quilombolas são de pescadores $(15,30 \%)$, seguidas de domésticas $(12,30 \%)$ e agricultores $(5,70 \%)$. 0 emprego formal, representado pela carteira de trabalho assinada, está presente em $0,60 \%$ da população acima de 18 anos. Cerca de $29,70 \%$ dos chefes de família declararam que nenhum membro de sua família recebia qualquer renda. Do contingente de trabaIhadores acima de 18 anos, 9,00\% declararam que recebiam, no máximo, meio salário-mínimo; $19,80 \%$, entre meio e um salário-mínimo; $21,26 \%$ recebiam de um a dois salários-mínimos; e 19,80\% , acima de dois salários-mínimos. Algumas famílias quilombolas declaram que recebem $\mathrm{R} \$ 15,00$ por mês ${ }^{18}$.

A visão de vulnerabilidade social é referida em relação à saúde e à doença. A morbimortalidade, tanto de origem infecto-contagiosa quanto crônico-degenerativa, compõe o repertório de reflexão da rede de causalidade da insegurança alimentar e nutricional.

Estamos esquecidos aqui. [....] quando alguém adoece, não sabemos como tratar da doença e não temos lugar para ir [...] morre gente aqui de doença que nem sabemos como aconteceu [...] já vi falar de tudo, hepatite, AIDS, problema de coração. Não adianta vocês do governo e da pesquisa ajudar a gente melhorando a produção de comida se tem a doença (Homem, 51 anos, pescador).

A importância do recorte étnico/racial na assistência e na atenção em saúde relativa às doenças e às condições de vida da população negra, permite que sejam identificados contingentes po pulacionais mais suscetíveis a agravos à saúde, como hipertensão e anemia falciforme ${ }^{21}$. 
Nesses quilombos, nenhuma das taxas de mortalidade alcançou níveis considerados satisfatórios, quando comparados com os parâmetros preconizados pelo M inistério da Saúde - de menos de 20 óbitos por mil nascidos-vivos. Foi referido que o diferencial na mortalidade de menores de um ano de idade para os quilombos da área de terra firme e várzea é de 30,4 óbitos por mil nascimentose de 50,2 óbitos por mil nascimentos, respectivamente. As taxas de mortalidade das comunidades quilombolas são maiores quando comparadas com a do País (27,0 óbitos por mil nascidos-vivos), da região Norte $(26,2 / 1.000$ nascidos-vivos) e da população negra rural do Estado do Pará (32,9 óbitos por mil) 22-24.

Os serviços básicos de saúde estão ausentes nas comunidades. 0 único quilombo que conta com um Posto de Saúde é a comunidade de Murumuru, que funciona como pólo de atendimento para todos os quilombos, em média distante a $70 \mathrm{~km}$. 0 atendimento, segundo a comunidade, não é adequado em razão da ausência de profissionais de saúde e agentes comunitários e da falta de medicamentos e infraestrutura. Observase que, nas urgências médicas, os doentes são transportados em um puxírum - meio de transporte feito por duas ou mais pessoas em rede, elaborado com lençóis. A pessoa é carregada pelas trilhas de terra até as avenidas da cidade de Santarém na espera de ser socorrida. Embora neste artigo os itinerários terapêuticos não sejam objetos de discussão, o exame dos fatores causais relacionados à atenção à saúde, revelou que são estabelecidos itinerários terapêuticos com base em práticas de medicina tradicional e no sistema de saúde vigente no País. De fato o uso da medicina tradicional guarda relação com a cultura destes grupos étnicos, porém a utilização desta não impossibilita que a comunidade recorra a outros sistemas de práticas de cura provavelmente com a incorporação de elementos externos, gerando uma concomitância ou hibridação entre os processos, mesmo que o modelo de pensamento médico vigente não estimule a convivência com outros sistemas ${ }^{25,26}$.
O debate sobre a insegurança alimentar e nutricional nas comunidades quilombolas foi relacionado à ilusão e ao medo. Este ramo causal foi priorizado pelo GF para discutir os aspectos positivos e negativos da abertura da rodovia. Os representantes da comunidade vêem a pavimentação da rodovia como uma ação de ilusão de um novo eldorado (Anexo).

O uso da figura mitológica de novo eldorado pelos representantes quilombolas resgata uma expressão simbólica relacionada à conquista das Américas pelos europeus, juntamente com o mito das amazonas ${ }^{27}$. Este mito, resgatado pelos representantes quilombolas para declarar sua compreensão com a pavimentação da Rodovia BR-163, foi usado com a mesma compreensão do advento da extração de ouro em garimpos na Amazônia. Seu conceito, para os representantes quilombolas, expressa a idéia de fronteiras de riquezas e desenvolvimento econômico a serem desbravadas.

[...] a gente fala muito aqui que a BR-163 é um novo eldorado igual aos garimpos que são descobertos aqui na região. Vem gente de tudo quanto é lugar para ganhar dinheiro [...] tudo se desenvolve, tanto as coisas ruim como as boas [...] (M ulher, 33 anos, professora de ensino fundamental).

O novo eldorado revela a visão dialética do desenvolvimento econômico da região. Para a comunidade quilombola, a rodovia vai atrair produtores rurais, principalmente os interessados na produção de soja, das regiões Sudeste e Sul, sem preocupação com a realidade social da região. Estes desbravadores em busca de terras farão uma valorização ilusória dos preços das terras quilombolas, o que estimulará a venda das terras, principalmente pelos moradores mais jovens. 0 temor revelado é que isto, embora seja bom, contribua para a perda de identidade quilombola, ocasionando fome, miséria e racismo.

[...] agora eu comecei a pensar o que eu não tinha pensado: a BR-163 vai trazer mais gente para cá. Vai ter muito "gaúcho" querendo plantar soja e vai expulsar a 
gente daqui com dinheiro. $E$ isto pode acontecer. [...] muitos quilombolas vão vender suas terras iludidos que lucraram, mas vão acabar morando naquela favelinha que existe em Santarém [...] muito carro passando pelas nossas comunidades, é muito forasteiro, trazendo as drogas. Será que eles pensam que a gente continua "nego bobo"?" (Homem, 43 anos, pescador).

[...] o quilombola vai ficar iludido. Para os de fora é um novo eldorado. Eles pensam em terra para plantar soja e criar gado. Para o quilombola é o progresso chegando. Vai ter luz elétrica e todo mundo vai querer comprar televisão, fogão, geladeira e depois o caminhão da loja vai vim pegar porque o dinheiro acabou [...] (Homem, 23 anos, pescador).

A pavimentação da Rodovia BR-163 foi priorizada por várias ações do Governo Federal com o propósito de melhorar a economia local de municípios e localidades e favorecer a inclusão social da população próxima à sua área de abrangência. As iniciativas governamentais têm atuado a partir de estratégias que contribuam para amenizar impactos sociais e ambientais negativos na região, com destaque para migrações desordenadas, ocupação irregular de terras públicas, desmatamento e exploração não-sustentável dos recursos naturais e aumento de criminalidade e piora do quadro de morbimortalidade.

A iniciativa do governo em finalizar a pavimentação dessa rodovia é compreendida como uma estratégia de grande impacto econômico. A situação é vista pelos setores governamentais como uma estratégia de inclusão social, para os quilombolas, por sua vez, há o medo do que poderá acontecer em seu cotidiano.

As razões da desconfiança remetem ao passado. A abolição da escravidão, há 117 anos, empreendeu uma política de exclusão e racismo. A implantação de ações e programas afirmativos e de inclusão social da população negra é recente e está no cenário dos movimentos sociais polemizados em razão da estratégia da política de cotas implantada pelo governo. Isso tem gerado incertezas e dúvidas ${ }^{28}$. Esse conflito é identificado pelos líderes quilombolas e vivido em seu cotidiano, quando vão lutar pela titulação de suas terras, por escolas para seus filhos mais próximas de suas residências, por assistência à saúde e por financiamento para projetos de melhoria de suas condições de vida.

A desconfiança e o temor são os reconhecimentos de que o racismo ainda está fortemente presente na sociedade brasileira. 0 racismo está internalizado e propagado intra e intergerações e a memória perversa da exclusão social é marcante $^{29}$. No Brasil, esta situação tem faces ocultas e existem formas de expressão menos evidentes e que não desafiam as normas sociais ${ }^{29-31}$. Essa realidade é aprendida pelos líderes quilombolas em seu cotidiano de atuação nos movimentos sociais. A busca da inclusão social não é compreendida como algo a ser dado e sim conquistado por meio de muita luta.

[...] eu não vejo outro jeito do que a gente se prevenir para isto que vai acontecer [...] é mais uma luta [...] tenho medo da força de tudo isto ser maior do que a gente [...] mas vamos achar forças para lutar [...] temos companheiros como vocês para ajudar a alertar a gente [...] fica mais fácil quando a gente se prepara. Nós vamos se preparar (Homem, 43 anos, pescador).

A inclusão social da população negra não pode ser assumida por leis de mercado e por políticas universalistas. As iniciativas de propostas de ações e políticas para combater todas as formas de discriminação enfrentam o desafio de superação do racismo institucional. No Brasil este problema ainda está expresso no discurso de alguns segmentos de governo e de teóricos, o que tem contribuído para retardar a implementação de ações de inclusão social para a população negra e quilombola ${ }^{32,33}$. 
A preocupação com os problemas decorrentes da abertura da BR-163, na opinião dos quilombolas, pode ser superada com a participação da comunidade no processo, como a proposição de fóruns de acompanhamento do processo de pavimentação e de ações de promoção do etnodesenvolvimento da região, o que, para a maioria das lideranças locais, contribui para evitar efeitos perversos. Nesse sentido, a opção por uma produção que valorize a herança cultural deve prevalecer. Esta opção constitui o referencial para pensar as novas formas de organização social do espaço que vem se configurando no território. 0 conceito de etnodesenvolvimento assume a territorialidade como o regime de propriedade comum e de sentido de pertencimento a um contexto específico defendido e reafirmado, o qual está ligado à profundidade histórica da ocupação guardada na memória coletiva ${ }^{34,35}$.

A sobrevivência das comunidades quilombolas nesses territórios tem se caracterizado também por uma invisibilidade social que se vincula à marginalidade econômica e a sua localização em áreas intersticiais dos centros econômicos como resultado dos interesses do mercado capitalista por diversos recursos naturais e de terras. Para isso, é necessário reconstruir o processo de participação da comunidade a fim de melhorar as relações institucionais com todas as esferas de governo e com a população. Há necessidade dos representantes governamentais superarem 0 racismo institucional; em relação à comunidade, é preciso apagar as nódoas do passado relativas à desconfiança decorrente de frustrações dos movimentos sociais. Para isto são necessárias à reconstrução conceitual e a proposição de políticas públicas com base na análise das relações entre os arcabouços institucionais, as regras do jogo político-social e a atuação dos atores sociais ${ }^{33}$.

\section{CONSIDERAÇÕ ES FINA IS}

A compreensão segundo a qual a rede de causalidade relativa à pavimentação da Rodovia BR-163 pode propiciar a insegurança alimentar e nutricional, por meio do aumento da fome e da miséria e do racismo, foi a expressão representada pelos quilombolas. Embora os núcleos de sentido encontrados na pesquisa tenham relacionado de forma negativa o processo de pavimentação da rodovia, a população quilombola quer se preparar para esses problemas. Portanto, encontrar formas de participação popular com as instituições governamentais e não-governamentais é a estratégia a ser adotada.

A experiência de construção coletiva, principalmente no campo de pesquisa científica, também deve incorporar estratégias participativas, com o envolvimento dos pesquisadores e da comunidade. A construção de um modelo de causalidade sobre essa problemática com a população quilombola foi uma estratégia muito eficiente. Esse método, ao trabalhar com os pressupostos da participação popular voltados para uma construção coletiva, permitiu a discussão ampliada da problemática do desenvolvimento econômico e de suas conseqüências positivas e negativas para as comunidades quilombolas de Santarém. Tal estratégia, em um projeto de pesquisa, acentua a importância do compromisso dos pesquisadores em utilizar abordagens metodológicas ampliadas, para responder à complexidade de um fenômeno que trabalha com variáveis quantitativas e qualitativas. Portanto, a experiência de utilização de um méto do participativo permite a reflexão sobre 0 papel da pesquisa como estratégia de co-responsabilidade na superação de todas as formas de discriminação étnica e social ${ }^{36}$.

A insegurança alimentar, reconhecida pela comunidade como uma ameaça ao etnodesenvolvimento, expôs que há fronteiras a serem vencidas, em que a miséria, a fome, o racismo e a ignorância conjugam forças poderosas para a exclusão social. Assim, a busca de construção de espaços democráticos representativos e deliberativos, como expressão de um portal dialógico entre as instituições e a comunidade, é a principal estratégia para a superação de qualquer efeito perverso às condições de vida das populações que habitam próximas à construção e à pavimentação da Rodovia BR-163. 


\section{COLABORADORES}

D. OLIVEIRA e SILVA, responsável pela consolidação das informações e pela elaboração da metodologia de confecção dos modelos causais junto à comunidade quilombola. A.F.H. GUERRERO, responsável pela discussão e pela pesquisa bibliográfica sobre saúde e etnia. C.H. GUERRERO, responsável pelas análises estatísticas e pela revisão final das informações publicadas no artigo. L.M. TOLEDO, participação no trabalho de campo nas áreas quilombolas nos temas relacionados à epidemiologia e ao geo-processamento. Contribuiu com a pesquisa bibliográfica sobre demografia e perfil de saúde e com a revisão do texto.

\section{RE FERÊ N C IAS}

1. Parodi TC. Equidad en salud: uma mirada desde la perspectiva de la etnicidad [versión preliminar]. Washington (DC): OPS/OM S; 2001. p.24.

2. Brasil. Fundação Cultural Palmares. Sistema de informações de comunidades afro-brasileiras: SICAB; 2007 [acesso 2004 Set 24]. Disponível em: $<$ http//www. palmares.gov.br>.

3. Valente FLS. Segurança Alimentar Nutricional. [acesso 2007 jul 23]. Disponível em: <www.consea. mg-gv.br/documentos/seguranca_alimentar_ nutricional.pdf $>$.

4. Belik W. Perspectivas para segurança alimentar e nutricional no Brasil. Rev Saúde Soc. 2003; 12(1): 12-20.

5. Brasil. Conselho Nacional de Segurança Alimentar e Nutricional. III Conferência Nacional de Segurança Alimentar e Nutricional: documento de base. Brasília; 2007. p.6.

6. Brasil. Conselho Nacional de Desenvolvimento Científico. Edital MCT/CNPq/MS-SCTIE-DECIT, no 034/2005 [acesso 2007 maio 17]. Disponível em: <http//memória.cnpq.br/resultados julgamento/2005/edital_0342005_2.htm>.

7. Lefevre P, Suremain CE, Sejas E. Combining causal model and focus group discussions experiences learned from a socio-antropological research on the differing perceptions of caretakers and health professionals on children's health (Bolivia/Peru). Qualitative Rep. 2004; 9(1):1-17.

8. Víctora CG. Pesquisa qualitativa em saúde: uma introdução ao tema. Porto Alegre: Tomo; 2000.

9. Minayo MC. Pesquisa social: teoria método e criatividade. Petrópolis: Vozes; 2003.
10. Beghin I, Dujardin B. A guide to nutritional assessment. Geneva: World Health Organization; 1988.

11. Beghin I. L'Approche causale en nutrition. In: Lemmonier $D$, Ingenbleek $Y$, editors. La malnutrition dans le pays du Tiers-Monde. Paris: INSERM ; 1989. p.615-28.

12. Gomes R, Alves EM, Pontes MLM.As representações sociais e a experiência da doença. Cad Saúde Pública. 2002; 18(5):1207-14.

13. Gomes FS. Histórias de Quilombolas: mocambos a comunidades de senzalas no Rio de Janeiro, século XIX. São Paulo: Companhia das Letras; 2006. p.430.

14. Santos G, Santos AC. Sustentabilidade da pesca na Amazônia. Estud Av. 2005; 19(54):165-82.

15. Oliveira PTR. O sistema único de saúde, descentralização e a desigualdade regional. Um enfoque sobre a região da Amazônia Legal [tese]. Rio de Janeiro: ENSP; 2005.

16. Buainain AM, Romeiro A, Guanziroli R. A agricultura familiar e o novo mundo rural. Sociologias. 2003; 10:312-47.

17. Brasil. Diagnóstico sócio-econômico-cultural das comunidades remanescentes de quilombos. Relatório geral. Brasília: Fundação Cultural Palmares; 2004.

18. Silva DO, Guerrero AFH, Toledo LM. Reflexos do singular na desigualdade social: os diversos sentidos da fome em quilombos na Região Norte, Brasil. In: Lienhard M, organizador. Discursos sobre a pobreza: América Latina e países africanos. Zurique: Ibero-Americana Libros; 2006. p.442.

19. Almeida AFWB. Terras de quilombos, terras de indígenas, babaçuas livres, castanhas do povo, faxinais de pastos: terras tradicionalmente ocupadas. Manaus: UFAM ; 2006.

20. Heringer R. Desigualdades raciais no Brasil: síntese de indicadores e desafios no campo das políticas públicas. Cad Saúde Pública. 2002; 18(Suplemento):57-65.

21. Oliveira F. Saúde reprodutiva, etnicidade e políticas públicas no Brasil. In: Monteiro S, Sansone O, organizadores. Etnicidade na América Latina: um debate sobre raça e direitos reprodutivos. Rio de Janeiro: FIOCRUZ; 2004. p.344.

22. Guerrero AFH, Silva DO, Guerrero CH, Toledo LM, Teixeira P. M ortalidade infantil em remanescentes de quilombos do município de Santarém, Pará, Brasil. Saúde Soc. 16(2):103-10.

23. Programa das Nações Unidas para o Desenvolvimento. Projeto do Milênio das Nações Unidas investindo no desenvolvimento: um plano para 
atingir objetivos de desenvolvimento do milênio. Washington (DC): Grundy \& Northedge; 2005.

24. Brasil. M inistério da Saúde. Estimativas de mortalidade infantil por micro-regiões e municípios. Brasília; 2005. [acesso 2006 set]. Disponível em: $<$ <ttp://www.datasus.gov.br>.

25. Foller ML. Intermedicalidade: a zona de contato criada por povos indígenas e profissionais de saúde. In: Langdon EJ, Garnelo L, organizadores. Saúde dos povos indígenas: reflexões sobre antropologia participativa. Rio de Janeiro: Associação Brasileira de Antropologia; 2004. p.129-47.

26. Gil LP. Políticas de saúde, pluralidade terapêutica e identidade na Amazônia. Saúde Soc. 2007; 16(2): 48-60

27. Coelho AW. Amazônia, mito e realidade. [acesso 2001 jul 10]. Disponível em: <www.vmgg8.ig. com.br/cronica.htm>.

28. Domingues $P$. Ações afirmativas para negros no Brasil: o início de uma reparação histórica. Rev Bras Educ. 2005; 29:164-76.

29. Henriques R. Desigualdade racial no Brasil: evolução das condições de vida na década de 90 . Brasília: IPEA; 2001. p.52.

30. Camino L, Silva P, Machado A, Pereira AC. A face oculta do racismo no Brasil: uma análise psicossociologica. Rev Psicol Política. 2001; 1(1):13-36.
31. M yers A. $O$ valor da diversidade racial nas empresas. Estud Afro-Asiat. 2003; 25(3):483-515.

32. Silverio VR. Ação afirmativa e o combate do racismo institucional no Brasil. Cad Pesq. 2002; 117:219-46.

33. Sampaio EQ. Discriminação racial e políticas públicas de caráter afirmativo no Brasil. Dados. 2004; 14(1):165-72.

34. Diniz SC, Magalhães FNC, M onte-M ór RLM. Economia e etnodesenvolvimento no território indígena Xakriabá, M G. Anais do XII Seminário sobre Economia M ineira. Diamantina: CEDEPLAR; 2006. p.22.

35. Little PE. Territórios sociais e povos tradicionais no Brasil: por uma antropologia de territorialidade. Série antropológica. Brasília: Universidade de Brasília; 2002. p.332.

36. Lopes F. Para além da barreira dos números: desigualdades raciais e saúde. Cad Saúde Pública. 2005; 21(5):1595-601.

37. Fundação Oswaldo Cruz. Rede de causalidade, Santarém, Brasília, Distrito Federal. [elaborado em maio de 2006] Rio de Janeiro; 2006.

Recebido em: 17/5/2007

Versão final reapresentada em: 14/11/2007 Aprovado em: 26/2/2008 


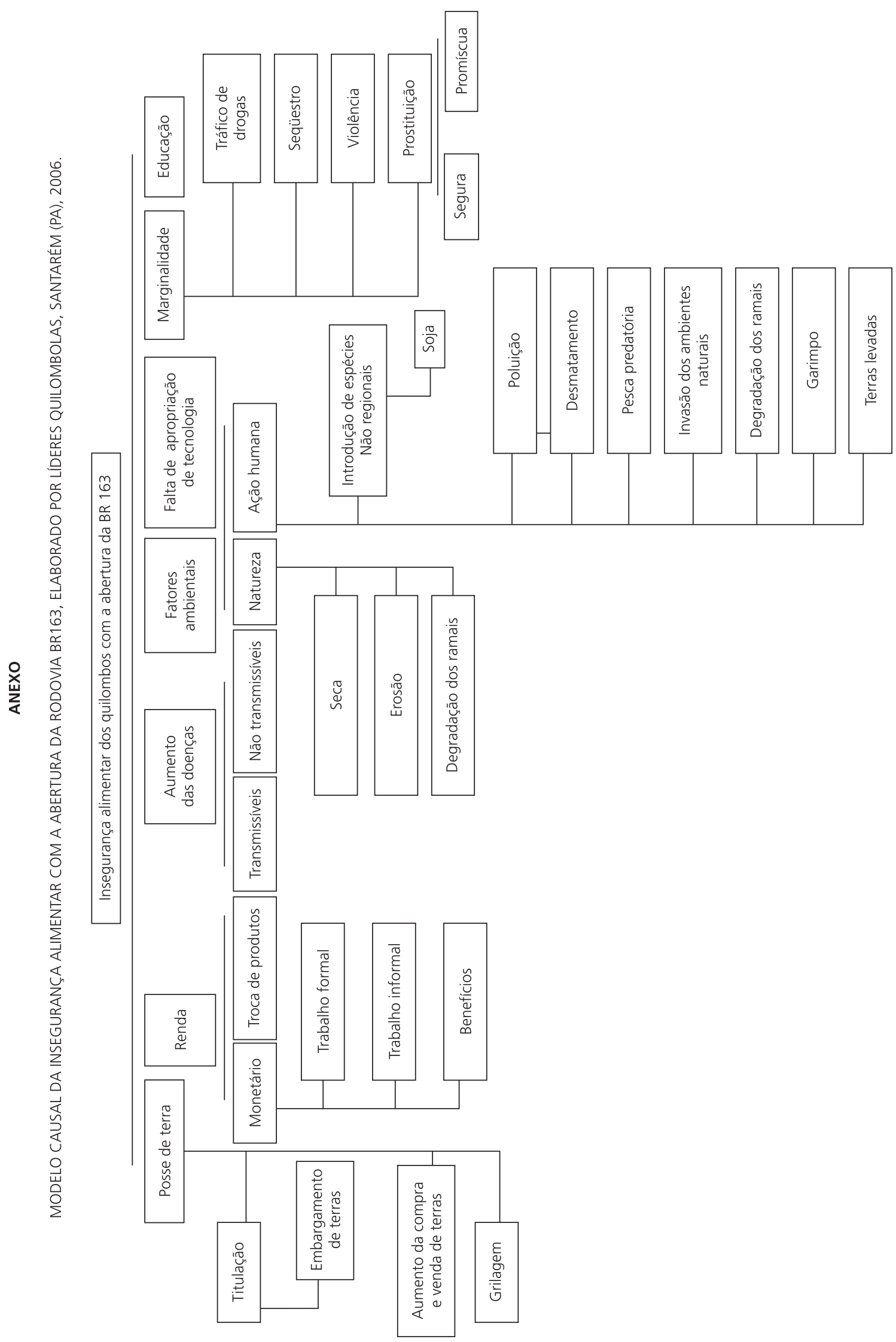


